\title{
Genetics of alternative definitions of feed efficiency in grazing lactating dairy cows
}

\author{
A. M. Hurley, ${ }^{\dagger}$ N. López-Villalobos, $†$ S. McParland, ${ }^{*}$ E. Lewis, ${ }^{*}$ E. Kennedy, ${ }^{*}$ M. O'Donovan, ${ }^{*}$ J. L. Burke, $†$ \\ and D. P. Berry ${ }^{\star 1}$ \\ *Teagasc, Animal and Grassland Research and Innovation Centre, Moorepark, Fermoy, Co. Cork, Ireland \\ †Institute of Veterinary, Animal and Biomedical Sciences, Massey University, Private Bag 11-222, Palmerston North, New Zealand
}

\begin{abstract}
The objective of the present study was to estimate genetic parameters across lactation for measures of energy balance (EB) and a range of feed efficiency variables as well as to quantify the genetic inter-relationships between them. Net energy intake (NEI) from pasture and concentrate intake was estimated up to 8 times per lactation for 2,481 lactations from 1,274 HolsteinFriesian cows. A total of 8,134 individual feed intake measurements were used. Efficiency traits were either ratio based or residual based; the latter were derived from least squares regression models. Residual energy intake (REI) was defined as NEI minus predicted energy requirements [e.g., net energy of lactation $\left(\mathrm{NE}_{\mathrm{L}}\right)$, maintenance, and body tissue anabolism] or supplied from body tissue mobilization; residual energy production was defined as the difference between actual $\mathrm{NE}_{\mathrm{L}}$ and predicted $\mathrm{NE}_{\mathrm{L}}$ based on NEI, maintenance, and body tissue anabolism/catabolism. Energy conversion efficiency was defined as $\mathrm{NE}_{\mathrm{L}}$ divided by NEI. Random regression animal models were used to estimate residual, additive genetic, and permanent environmental (co) variances across lactation. Heritability across lactation stages varied from 0.03 to 0.36 for all efficiency traits. Within-trait genetic correlations tended to weaken as the interval between lactation stages compared lengthened for EB, REI, residual energy production, and NEI. Analysis of eigenvalues and associated eigenfunctions for EB and the efficiency traits indicate the ability to genetically alter the profile of these lactation curves to potentially improve dairy cow efficiency differently at different stages of lactation. Residual energy intake and EB were moderately to strongly genetically correlated with each other across lactation (genetic correlations ranged from 0.45 to 0.90 ), indicating that selection for
\end{abstract}

Received November 15, 2016.

Accepted March 18, 2017.

${ }^{1}$ Corresponding author: donagh.berry@teagasc.ie lower REI alone (i.e., deemed efficient cows) would favor cows with a compromised energy status; nevertheless, selection for REI within a holistic breeding goal could be used to overcome such antagonisms. The smallest (8.90\% of genetic variance) and middle $(11.22 \%$ of genetic variance) eigenfunctions for REI changed sign during lactation, indicating the potential to alter the shape of the REI lactation profile. Results from the present study suggest exploitable genetic variation exists for a range of efficiency traits, and the magnitude of this variation is sufficiently large to justify consideration of the feed efficiency complex in future dairy breeding goals. Moreover, it is possible to alter the trajectories of the efficiency traits to suit a particular breeding objective, although this relies on very precise across-parity genetic parameter estimates, including genetic correlations with health and fertility traits (as well as other traits).

Key words: random regression model, heritability, energy, residual energy intake, feed intake

\section{INTRODUCTION}

The gross efficiency of converting feed energy to milk in dairy cows has more than doubled over the past century, largely as the indirect consequence of increased milk output per cow (Oltenacu and Broom, 2010). Reducing feed intake, without repercussions for the other performance traits, is important to maintain dairy sector competitiveness while also meeting projected consumer demands for animal protein within the realm of constrained resources. Improving feed efficiency is also desirable because of its potential benefits toward reducing both nutrient and greenhouse gas emissions per animal. The importance of feed efficiency to the dairy industry is well recognized and has led to a largescale global effort to improve this animal characteristic (Berry et al., 2014; de Haas et al., 2015).

Genetic selection for feed efficiency is common in pigs and poultry (Emmerson, 1997; Lonergan et al., 2001), but it is not explicitly considered in most dairy 
cow breeding objectives. Its omission from the dairy cow breeding objective is due to both a lack of available feed intake data from which to estimate net feed efficiency, but also the lack of a consensus on the most appropriate definition of net feed efficiency in dairy cows. Several feed efficiency definitions have been proposed and have been the subject of extensive discussion. Hurley et al. (2016) described the phenotypic (co)variances among a range of different definitions of feed efficiency in grazing lactating dairy cows. Less well known, however, is the genetic (co)variance among these alternative definitions of feed efficiency. Most of the studies on the genetics of the feed intake complex have been derived from dairy cows in confined production systems, and assumed feed efficiency was genetically the same trait throughout lactation (Manzanilla-Pech et al., 2014; Manafiazar et al., 2016). The existence of genetic variation in alternative definitions of feed efficiency, as well as the estimation of precise intra- and intertrait genetic correlations, needs to be quantified before consideration in genetic evaluations and subsequent inclusion in breeding objectives. The objective of the present study was to estimate genetic parameters across lactation for a range of alternative measures of feed efficiency in grazing lactating Holstein-Friesian dairy cows, and quantify the genetic intra- and interrelationships among these alternative definitions.

\section{MATERIALS AND METHODS}

\section{Data}

Data were collected from the Animal and Grassland Research and Innovation Centre, Teagasc Moorepark, Fermoy, Co. Cork, Ireland, between the years 1995 to 2014, inclusive. All studies were undertaken on 2 adjacent research farms, namely Curtin's Research Farm and the Moorepark Research Farm located in southern Ireland (latitude $52^{\circ} 9^{\prime} \mathrm{N}$; longitude $8^{\circ} 16^{\prime} \mathrm{W}$ ). The majority of cows used in the present study originated from several controlled experiments, which evaluated alternative grazing strategies, nutritional strategies, or strains of Holstein-Friesian animals; a description of the database is provided by Hurley et al. (2016). Individual animal grass DMI at pasture was periodically estimated using the n-alkane technique (Mayes et al., 1986). Details on the procedures used to collect and analyze fecal grab samples have been provided elsewhere (Kennedy et al., 2008). The procedure provides a measure of DMI averaged across $6 \mathrm{~d}$ of sampling. All cows were offered a basal diet of grazed grass. Perennial ryegrass (Lolium perenne) was the predominant pasture species at both research farms, and pastures were managed under a rotational grazing system comparable to that detailed by
Dillon et al. (1995). Some animals were supplemented with concentrates (depending on feeding protocol), varying from 0.89 to $3.9 \mathrm{~kg}$ of DM per cow daily, offered in equal feeds during each milking.

Cows were milked twice daily at 0700 and $1500 \mathrm{~h}$ and individual cow milk yield was recorded daily; milk fat, protein, and lactose concentration was determined from successive evening and morning milk samples once per week using mid-infrared spectroscopy (FT6000, FOSS, Hillerod, Denmark). Net energy requirement for lactation was calculated as follows (Agabriel, 2007):

$$
\begin{aligned}
\mathrm{NE}_{\mathrm{L}}= & (0.054 \times \mathrm{FC}+0.031 \times \mathrm{PC}+0.028 \\
& \times \mathrm{LC}-0.015) \times \text { milk kg},
\end{aligned}
$$

where $\mathrm{FC}$ is fat concentration (\%), $\mathrm{PC}$ is protein concentration (\%), and LC is lactose concentration (\%).

Individual animal live weight (BW) was generally measured weekly following morning milking using an electronic scale (Tru-Test Limited, Auckland, New Zealand). The scales were calibrated weekly against known weights. Body condition score on a scale of 1 (emaciated) to 5 (obese) was assessed by trained scorers every 2 to 3 wk in increments of 0.25 (Edmonson et al., 1989). Cubic splines with 6 knot points at 20, 70, 120, 170, 220 , and 270 DIM, with a covariance structure fitted among knot points, were fitted through individual live weight and BCS records. Live weight and BCS at each DIM were interpolated from the fitted splines. Forward differencing was used to estimate daily live weight and BCS change at each DIM. Individual cow daily total DMI (i.e., grazed pasture DMI plus concentrate DMI) was available up to 8 times (average of 4.5 times) per lactation.

Energy values of the pasture and concentrate were based on the French net energy system where 1 unité fourragère du lait (UFL) is the net energy requirements for lactation equivalent of $1 \mathrm{~kg}$ standard air-dry barley (Jarrige, 1989) equivalent to 7.11 MJ of net energy or 11.85 MJ of ME. The UFL concentration of the offered herbage was calculated using the ADF and $\mathrm{CP}$ concentration, which were measured in the laboratory (Jarrige, 1989). Concentrate UFL value was also calculated from the chemical composition of the feed. The net energy content of the concentrate offered was calculated for each day; where UFL content of concentrate was not available (i.e., $26 \%$ of test-day records), the year-month average was assumed. Where the net energy content of the offered herbage (UFL $/ \mathrm{kg}$ of DM) was not available (i.e., $8 \%$ of test-day records), the year-month average was assumed. Total net energy intake (NEI) was defined as the sum of pasture and concentrate NEI. 


\section{Data Editing}

Obvious data errors for BW, BCS, and the milk production traits (i.e., milk yield, fat yield, protein yield, lactose yield) were discarded. Only data between 8 and 280 DIM were retained. Parity was categorized as 1, 2, and $\geq 3$.

Contemporary group of experimental treatment by test-date was defined for NEI, BW, BCS, milk yield, and composition. Contemporary groups with less than 5 observations were discarded. Following edits, the final data set contained 97,376 test-day records from 2,481 lactations on 1,274 cows; 8,134 individual feed intake measurements remained.

The pedigree of all cows was traced back at least 4 generations, where available. Animals with no recorded sire or dam $(\mathrm{n}=16)$ were excluded from the analysis. The average number of daughters per sire was 5.87 .

\section{Definitions of Energy Efficiency and Energy Balance}

Definitions of all traits have been previously described in detail by Hurley et al. (2016). Energy balance (EB) for each test-day was calculated in accordance with the net energy system outlined by Jarrige (1989) and modified for Irish dairy systems by O'Mara (1996):

$$
\mathrm{EB}=\mathrm{NEI}-\Delta \mathrm{NE}-\mathrm{NE}_{\mathrm{L}}-\mathrm{NE}_{\mathrm{M}}-\mathrm{NE}_{\mathrm{P}},
$$

where NEI is daily net energy intake, $\triangle \mathrm{NE}$ is an adjustment of daily net energy intake for the proportion of concentrates in the diet, $\mathrm{NE}_{\mathrm{L}}$ is daily net energy requirements for lactation, $\mathrm{NE}_{\mathrm{M}}$ is daily net energy for maintenance calculated as $(1.4+0.6 \times$ live weight $/ 100)$ $\times 1.2$, and $\mathrm{NE}_{\mathrm{P}}$ is daily net energy requirements for pregnancy (O'Mara, 1996).

Residual-Based Efficiency Traits. Residual energy intake (REI) for each day of lactation was defined as the residuals from the regression of NEI on energy sinks and other energy sources as

$\mathrm{REI}=\mathrm{NEI}-\left[\begin{array}{l}\mathrm{NE}_{\mathrm{L}}+\text { parity }+\sum_{i=1}^{2} \mathrm{DIM}^{i}+\mathrm{BW}^{0.75}+\mathrm{BCS}+ \\ \mathrm{BW}^{0.75} \times \mathrm{BCS}+\Delta \mathrm{BW}^{+}+\Delta \mathrm{BW}^{-}+ \\ \Delta \mathrm{BCS}^{+}+\Delta \mathrm{BCS}^{-}+\Delta \mathrm{BW}^{+} \times \mathrm{BCS}^{-} \\ \Delta \mathrm{BW}^{-} \times \mathrm{BCS}\end{array}\right]$,

where REI is daily residual energy intake, NEI is daily net energy intake, $\mathrm{NE}_{\mathrm{L}}$ is daily net energy requirements for lactation, parity $(1,2, \geq 3), \sum_{i=1}^{2} \operatorname{DIM}^{i}$ is days in milk included as a continuous variable with a linear $(i=1)$ and quadratic effect $(i=2)$, and $\mathrm{BW}^{0.75}$ is metabolic live weight. The energy generated from a $1 \mathrm{~kg}$ loss in live weight is less than the energy required for a $1 \mathrm{~kg}$ gain in live weight (O'Mara, 1996); therefore, piecewise regression was applied to live weight and BCS in the REI model where $\Delta \mathrm{BW}^{+}$describes animals gaining live weight, $\Delta \mathrm{BW}^{-}$describes animals losing live weight, $\triangle \mathrm{BCS}^{+}$describes animals gaining $\mathrm{BCS}$, and $\triangle \mathrm{BCS}^{-}$ describes animals losing BCS. No multicollinearity existed in the multiple regression model.

Analogous to residual gain in growing cattle (Koch et al., 1963), residual energy production (REP) for each day of lactation was defined from the residuals of a least squares regression model regressing net energy of lactation on NEI plus energy sinks and other energy sources, similar to that described by Coleman et al. (2010).

$$
\mathrm{REP}=\mathrm{NE}_{\mathrm{L}}-\left[\begin{array}{l}
\mathrm{NEI}+\text { parity }+\sum_{i=1}^{2} \mathrm{DIM}^{i}+\mathrm{BW}^{0.75}+\mathrm{BCS}+ \\
\mathrm{BW}^{0.75} \times \mathrm{BCS}+\Delta \mathrm{BW}^{+}+\Delta \mathrm{BW}^{-}+ \\
\Delta \mathrm{BCS}^{+}+\Delta \mathrm{BCS}^{-}+\Delta \mathrm{BW}^{+} \times \mathrm{BCS}+ \\
\Delta \mathrm{BW}^{-} \times \mathrm{BCS}
\end{array}\right],
$$

where REP is daily residual energy production, $\mathrm{NE}_{\mathrm{L}}$ is daily net energy requirements for lactation, NEI is daily net energy intake, parity $(1,2, \geq 3), \sum_{i=1}^{2} \operatorname{DIM}^{i}$ is days in milk included as a continuous variable with a linear and quadratic effect, $\mathrm{BW}^{0.75}$ is metabolic live weight, $\Delta \mathrm{BW}^{+}$describes animals gaining live weight, $\triangle \mathrm{BW}^{-}$describes animals losing live weight, $\triangle \mathrm{BCS}^{+}$ describes animals gaining $\mathrm{BCS}$, and $\triangle \mathrm{BCS}^{-}$describes animals losing BCS. No multicollinearity existed in the multiple regression model.

Ratio-Based Efficiency Traits. Energy conversion efficiency (ECE) for each day of lactation was defined as

$$
\mathrm{ECE}=\frac{\mathrm{NE}_{\mathrm{L}}}{\mathrm{NEI}}
$$

where $\mathrm{NE}_{\mathrm{L}}$ is the daily net energy requirements for lactation, and NEI is the daily net energy intake.

Metabolic efficiency (MEff) was defined as

$$
\mathrm{MEff}=\frac{\mathrm{NEI}-\mathrm{NE}_{\mathrm{L}}}{\mathrm{BW}^{0.75}}
$$


where $\mathrm{NEI}$ is daily net energy intake, $\mathrm{NE}_{\mathrm{L}}$ is net energy requirements for lactation, and $\mathrm{BW}^{0.75}$ is metabolic live weight.

Feed to live weight $(\mathbf{F t W})$ was defined as

$$
\mathrm{FtW}=\frac{\mathrm{NEI}}{\mathrm{BW}^{0.75}},
$$

where NEI is daily net energy intake, and $\mathrm{BW}^{0.75}$ is metabolic live weight.

Kleiber ratio (KR; Kleiber, 1961) in growing animals is defined as ADG divided by metabolic live weight. An analogous Kleiber ratio trait in dairy cattle was defined as

$$
\mathrm{KR}=\frac{\mathrm{NE}_{\mathrm{L}}}{\mathrm{BW}^{0.75}},
$$

where $\mathrm{NE}_{\mathrm{L}}$ is the net energy requirements for lactation and $\mathrm{BW}^{0.75}$ is metabolic live weight.

\section{Data Analysis}

All energy efficiency traits and EB followed a Gaussian distribution. Components of (co)variances for the efficiency traits and EB were quantified using random regression animal models across DIM in ASReml (Gilmour et al., 2009). Fixed effects included in the models were contemporary group, parity $(1,2$, and $\geq 3)$, as well as a 2-way interaction between parity and DIM. The most parsimonious fixed effect Legendre polynomial regression was based on visual inspection of the resulting lactation profile for each polynomial order. Although higher order polynomials for fixed effects fit the data better $(P<0.05)$, the lactation profiles of the quadratic and higher order polynomials were graphically almost identical for all traits. Random regressions using Legendre polynomials were used to model the additive genetic variance and within-lactation permanent environmental variance. A single across lactation permanent environment effect was also fitted.

Residual variances were estimated within 6 stages of lactation: 8 to 50 DIM, 51 to 100 DIM, 101 to 150 DIM, 151 to 200 DIM, 201 to 250 DIM, and >250 DIM. Within stage, residual variances were assumed to be homogeneous, whereas heterogeneity in residual variances was modeled across stages of lactation. No residual (co) variance was assumed among stages of lactation. The most parsimonious random regression model was determined by constantly increasing the order of the random regression for both the additive genetic component and permanent environmental component within-lactation. The lowest Akaike information criterion of converged models was the main statistical test to determine the most parsimonious model.

The genetic (co)variances across all DIM were estimated as

$$
\delta=\Phi^{\prime} \mathbf{K} \Phi,
$$

in which $\delta$ is the variance or (co)variance matrix for the efficiency traits and EB, $\boldsymbol{\Phi}$ is the matrix of Legendre polynomial regression coefficients, and $\mathbf{K}$ is the matrix of the additive genetic (co)variance matrix of the random polynomial coefficients. Standard errors of the heritability estimates were derived using a Taylor series expansion (Fischer et al., 2004).

Genetic correlations between the traits were estimated using a series of bivariate analyses in ASReml (Gilmour et al., 2009). Fixed and random effects included in the models were as previously described for the univariate models. The failure of some bivariate models to converge when a quadratic random regression was fitted necessitated the order of the fitted random regression to be linear. Such amendments had to be made for the correlations between EB with ECE, MEff, FtW, $\mathrm{KR}, \mathrm{REI}, \mathrm{NEI}, \mathrm{NE}_{\mathrm{L}}, \mathrm{BCS}$, and $\mathrm{BW}$; the correlations between ECE with MEff, FtW, KR, REI, REP, $\mathrm{NE}_{\mathrm{L}}$, NEI, and BW; the correlations between REI with MEff, FtW, REP, NEI, $\mathrm{NE}_{\mathrm{L}}, \mathrm{BCS}$, and BW; the correlations between RSP with MEff, FtW, NEI, $\mathrm{NE}_{\mathrm{L}}, \mathrm{BCS}$, and BW; the correlations between NEI with KR, MEff, and $\mathrm{BW}$; the correlations between $\mathrm{NE}_{\mathrm{L}}$ with MEff, FtW, $\mathrm{KR}$, and NEI; the correlations between BCS with MEff, FtW, NEI, and $\mathrm{NE}_{\mathrm{L}}$; and the correlations between $\mathrm{BW}$ with MEff, $\mathrm{FtW}$, and $\mathrm{NE}_{\mathrm{L}}$. Residual variances were estimated within each of the 6 DIM stages as described previously for the univariate analysis but a residual (co)variance between traits was also estimated.

Standard errors of genetic correlations were approximated using (Falconer and MacKay, 1996):

$$
\mathrm{SE}_{\mathrm{r}_{A_{x y}}}=\frac{1-\mathrm{r}_{A}^{2}}{\sqrt{2}} \sqrt{\frac{\mathrm{SE}\left(\mathrm{h}_{x}^{2}\right) \mathrm{SE}\left(\mathrm{h}_{y}^{2}\right)}{\mathrm{h}_{x}^{2} \mathrm{~h}_{y}^{2}}},
$$

where SE denotes the standard error, $\mathrm{r}_{A}$ is the genetic correlation between trait $x$ and trait $y$, and $\mathrm{h}^{2}$ is the heritability; the superscript $x$ or $y$ represents the respective traits under investigation.

To quantify the potential to genetically alter lactation profiles for each of the traits investigated, the eigenvalues and associated eigenfunctions were calculated (Kirkpatrick et al., 1990). The eigenvalues and eigenvectors were calculated from the decomposition of the additive genetic (co)variance matrix, and eigenfunc- 
Table 1. Number of observations (N), mean, order of the fixed effect Legendre polynomial and random effect Legendre polynomial used to model the additive genetic variance and within-lactation permanent environmental variance

\begin{tabular}{|c|c|c|c|c|c|}
\hline \multirow[b]{2}{*}{ Trait $^{1}$} & \multirow[b]{2}{*}{$\mathrm{N}$} & \multirow[b]{2}{*}{ Mean } & \multirow[b]{2}{*}{ Fixed } & \multicolumn{2}{|c|}{ Random } \\
\hline & & & & $\begin{array}{l}\text { Additive } \\
\text { genetic }\end{array}$ & $\begin{array}{c}\text { Permanent } \\
\text { environmental }\end{array}$ \\
\hline $\mathrm{EB}, \mathrm{UFL} / \mathrm{d}$ & 7,829 & 0.55 & 3 & 2 & 1 \\
\hline ECE & 7,829 & 0.60 & 3 & 2 & 2 \\
\hline MEff, UFL $/ \mathrm{kg}^{0.75}$ & 7,829 & 0.06 & 4 & 2 & 2 \\
\hline FtW, UFL $/ \mathrm{kg}^{0.75}$ & 7,829 & 0.15 & 4 & 2 & 1 \\
\hline $\mathrm{KR}, \mathrm{UFL} / \mathrm{kg}^{0.75}$ & 83,930 & 0.09 & 2 & 2 & 2 \\
\hline REI, UFL/d & 7,829 & 0.00 & 4 & 2 & 1 \\
\hline $\mathrm{REP}, \mathrm{UFL} / \mathrm{d}$ & 7,829 & 0.00 & 5 & 2 & 2 \\
\hline NEI, UFL/d & 8,134 & 16.23 & 3 & 2 & 2 \\
\hline $\mathrm{NE}_{\mathrm{L}}, \mathrm{UFL} / \mathrm{d}$ & 88,770 & 8.59 & 3 & 2 & 2 \\
\hline $\mathrm{BW}, \mathrm{kg}$ & 77,743 & 529.50 & 3 & 2 & 2 \\
\hline BCS, scale 1 to 5 & 37,063 & 2.84 & 3 & 2 & 2 \\
\hline
\end{tabular}

${ }^{1} \mathrm{~EB}=$ energy balance; ECE = energy conversion efficiency; MEff = metabolic efficiency; FtW = feed to live weight; $\mathrm{KR}=$ Kleiber ratio; $\mathrm{REI}=$ residual energy intake; $\mathrm{REP}=$ residual energy production; NEI $=$ net energy intake; BW = test-day live weight; $\mathrm{BCS}=$ test-day body condition score; UFL = unité fourragère du lait.

tions were subsequently calculated from the product of the eigenvectors and Legendre polynomial coefficients as

$$
\Psi_{i}(x)=\sum_{j=0}^{p-1}\left[k \Psi_{i}\right]_{j} \Phi_{j}(x),
$$

where $\left[k \Psi_{i}\right]_{j}$ is the $j$ th element of the $i$ th eigenvector, $\Phi$ is the $j$ th polynomial relating to the $p$ th order of fit, and $x$ is DIM.

\section{RESULTS}

Summary statistics, as well as the order of the fixed and random Legendre polynomials fitted to EB, the efficiency traits, and the production traits are in Table 1. Average test-day milk yield was $22.40 \mathrm{~kg} / \mathrm{d}$ with a standard deviation of $6.89 \mathrm{~kg} / \mathrm{d}$. Mean milk fat yield, milk protein yield, and milk lactose yield was $0.87,0.79$, and $1.06 \mathrm{~kg} / \mathrm{d}$, respectively. A quadratic random Legendre polynomial on the additive genetic effect best fitted the data for all production and efficiency traits (Table 1). For 3 (i.e., REI, FtW, and EB) out of the 12 traits evaluated, a quadratic random Legendre polynomial on the within-lactation permanent environmental effect failed to converge, so this effect was fitted as a linear polynomial (Table 1). Because a quadratic random regression was fitted to the additive genetic component for each trait, 3 eigenvalues existed. The percentage of variation accounted by the largest, middle, and smallest eigenvalues for the efficiency and production traits are in Table 2. The coefficient of genetic variation for $\mathrm{NE}_{\mathrm{L}}(6.74 \%)$ was greater than the coefficient of genetic variation for both REI (2.64\%) and NEI (4.82\%).

\section{Variance Components}

Estimated residual standard deviation for all traits was greatest in early lactation and generally decreased as the lactation progressed. The genetic standard deviation for $\mathrm{NE}_{\mathrm{L}}$ was greatest in very early lactation, declining thereafter, and varied from $0.88 \mathrm{UFL} / \mathrm{d}(280$ DIM) to $1.13 \mathrm{UFL} / \mathrm{d}$ (8 DIM). The genetic standard deviation for BW (1.10 kg at 39 DIM to $1.31 \mathrm{~kg}$ at 280 DIM) and BCS (1.93 BCS units at 29 DIM to 2.07 BCS units at 280 DIM) was greatest in late lactation (data not shown). The genetic standard deviation for EB and a selection of the efficiency traits across lactation are in Figure 1. The genetic standard deviation for REI across lactation (Figure 1) fluctuated from $1.28 \mathrm{UFL} / \mathrm{d}$ (34 DIM) to $1.74 \mathrm{UFL} / \mathrm{d}$ (280 DIM). Substantial genetic

Table 2. The percentage of variation accounted by the largest, middle, and smallest eigenvalues for the efficiency and production traits

\begin{tabular}{lccr}
\hline Trait $^{1}$ & $\begin{array}{c}\text { Largest } \\
(\%)\end{array}$ & $\begin{array}{c}\text { Middle } \\
(\%)\end{array}$ & $\begin{array}{c}\text { Smallest } \\
(\%)\end{array}$ \\
\hline EB, UFL/d & 67.42 & 20.93 & 11.65 \\
ECE & 71.67 & 24.04 & 4.29 \\
MEff, UFL/ $/ \mathrm{kg}^{0.75}$ & 74.15 & 22.30 & 3.55 \\
FtW, UFL $/ \mathrm{kg}^{0.75}$ & 92.13 & 6.85 & 1.01 \\
KR, UFL/kg & 82.49 & 15.47 & 2.04 \\
REI, UFL/d & 79.88 & 11.22 & 8.90 \\
REP, UFL/d & 77.17 & 18.09 & 4.74 \\
NEI, UFL/d & 93.28 & 6.13 & 0.60 \\
NE, UFL/d & 85.09 & 10.63 & 4.28 \\
BW, kg & 95.60 & 3.36 & 1.03 \\
BCS, scale 1 to 5 & 95.96 & 2.87 & 1.17 \\
\hline
\end{tabular}

${ }^{1} \mathrm{~EB}=$ energy balance; ECE $=$ energy conversion efficiency; MEff = metabolic efficiency; FtW = feed to live weight; $\mathrm{KR}=$ Kleiber ratio; $\mathrm{REI}=$ residual energy intake; $\mathrm{REP}=$ residual energy production; NEI = net energy intake; BW = test-day live weight; BCS = test-day body condition score; UFL = unité fourragère du lait. 


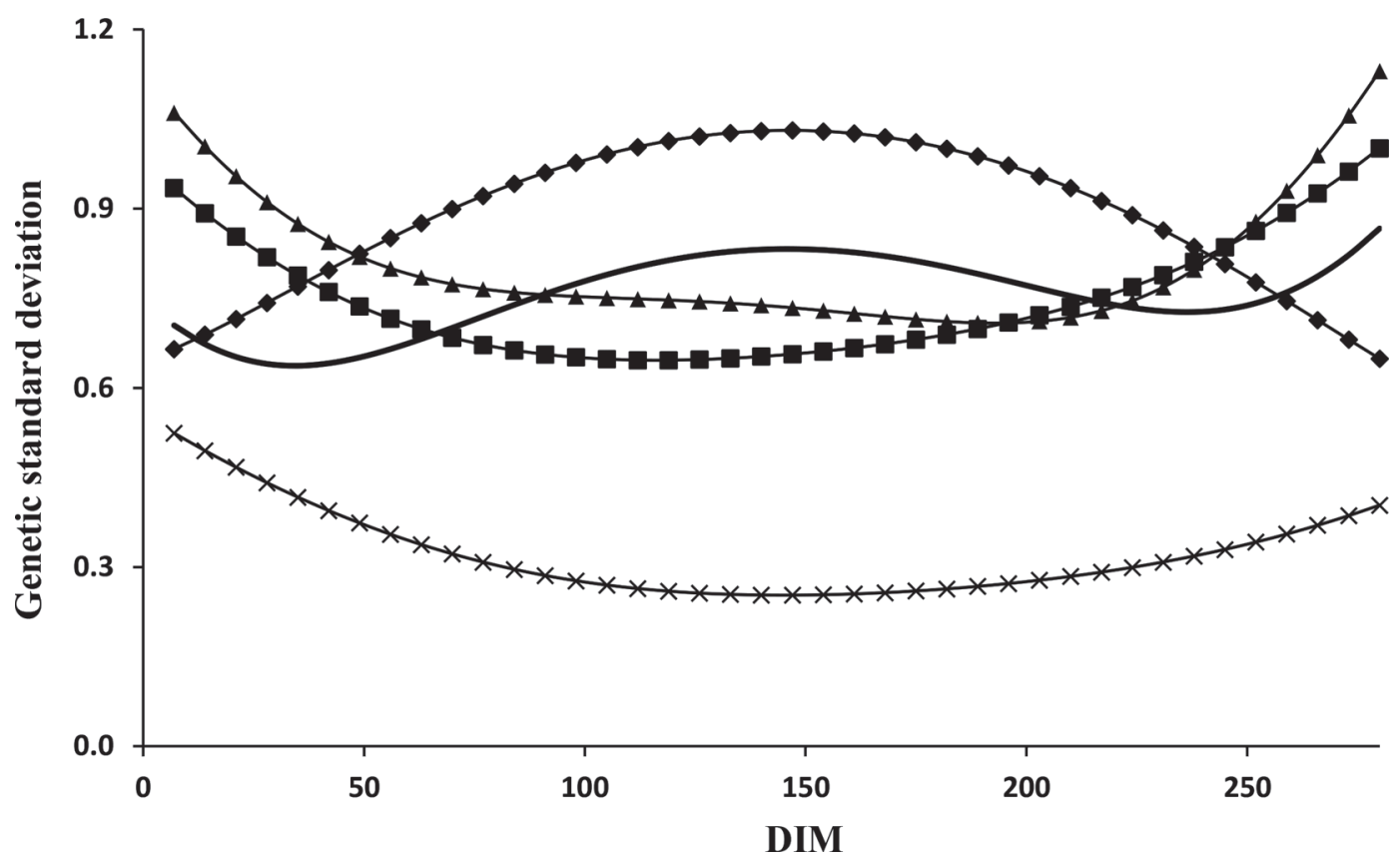

Figure 1. Genetic SD for energy balance (UFL/d; $\mathbf{\Delta}$ ), energy conversion efficiency $(\times)$, residual energy intake (UFL/d; 一), residual energy production $(\mathrm{UFL} / \mathrm{d} ; \mathbf{-})$, and net energy intake (UFL/d; $\bullet$ ). The genetic SD for residual energy intake and residual energy production were both rescaled, in that residual energy intake was divided by a factor of 2 and residual energy production was divided by a factor of 5 . UFL $=$ unité fourragère du lait.

variation was also evident across lactation for the ratiobased efficiency traits. The genetic standard deviation for MEff, FtW, and KR was greatest in early lactation, decreasing across DIM and varied from 0.39 to 0.64 $\mathrm{UFL} / \mathrm{kg}^{0.75}$ for MEff, from 0.67 to $0.82 \mathrm{UFL} / \mathrm{kg}^{0.75}$ for $\mathrm{FtW}$, and from 0.74 to $1.01 \mathrm{UFL} / \mathrm{kg}^{0.75}$ for KR (data not shown).

The eigenfunction associated with the largest eigenvalue for ECE was almost linear and positive across all DIM (Figure 2). The eigenfunction associated with the largest eigenvalue for REI was slightly curvilinear but nonetheless positive throughout lactation. Similar to ECE, the eigenfunction associated with the largest eigenvalue for REP was relatively linear and positive across all DIM.

Heritability estimates for EB, ECE, REI, REP, and NEI are in Figure 3. Heritability ranged from 0.06 (50 $\mathrm{DIM})$ to 0.18 (280 DIM) for EB, from 0.06 (50 DIM) to 0.28 (250 DIM) for ECE, from 0.04 (34 DIM) to 0.11 (280 DIM) for REI, from 0.12 (50 DIM) to 0.36 (250 DIM) for REP, and from 0.06 (8 DIM) to 0.28 (151 DIM) for NEI. The standard error for all heritability estimates for these traits was never greater than 0.08 (Figure 3). Summary statistics of the daily heritability estimates for the other efficiency and production traits are in Supplemental Table S1 (https://doi.org/10.3168/ jds.2016-12314).

\section{Genetic Correlations Within Trait in Different Stages of Lactation}

Within trait, genetic correlations at 8, 150, and 280 DIM with all other DIM for EB, ECE, REI, REP, and NEI are in Figure 4. Within-trait genetic correlations for MEff, FtW, and KR, at different DIM ranged from $-0.12( \pm 0.02)$ to $1.00( \pm 0.001), 0.64( \pm 0.01)$ to $1.00( \pm 0.001)$, and $0.50( \pm 0.01)$ to $1.00( \pm 0.001)$, respectively. The strength of the genetic correlations was inversely related to the interval between compared DIM; the weakest genetic correlations existed between 8 and 280 DIM. Within-trait genetic correlations for the production traits at different DIM ranged from 0.48 $( \pm 0.01)$ to $1.00( \pm 0.00)$ for $\mathrm{NE}_{\mathrm{L}}$, from $0.82( \pm 0.02)$ to $1.00( \pm 0.00)$ for $\mathrm{BW}$, and from $0.78( \pm 0.01)$ to 1.00 $( \pm 0.00)$ for BCS; the correlations weakened as the distance between time intervals compared increased.

\section{Genetic Correlations Between the Efficiency and Production Traits}

Genetic correlations across lactation between EB with ECE, MEff, REI, REP, NEI, $\mathrm{NE}_{\mathrm{L}}$, and BCS are in Figure 5. Energy balance was moderately genetically correlated with REI in early lactation $(0.45 \pm 0.18$ at 8 DIM), whereas near unity correlations existed in mid- 
a)

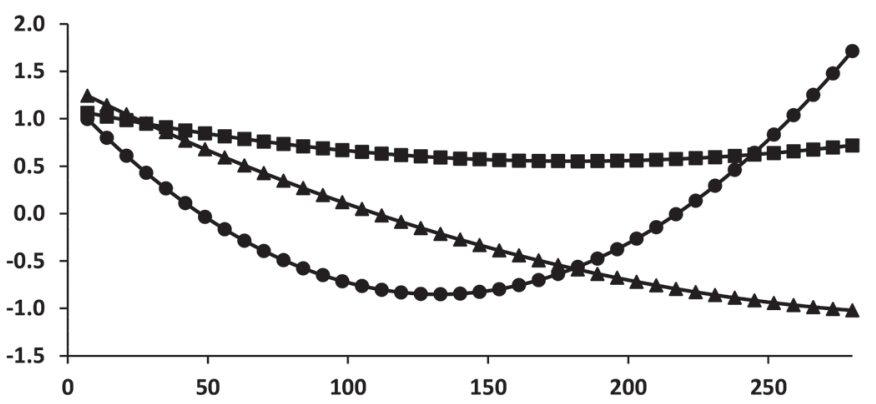

b)

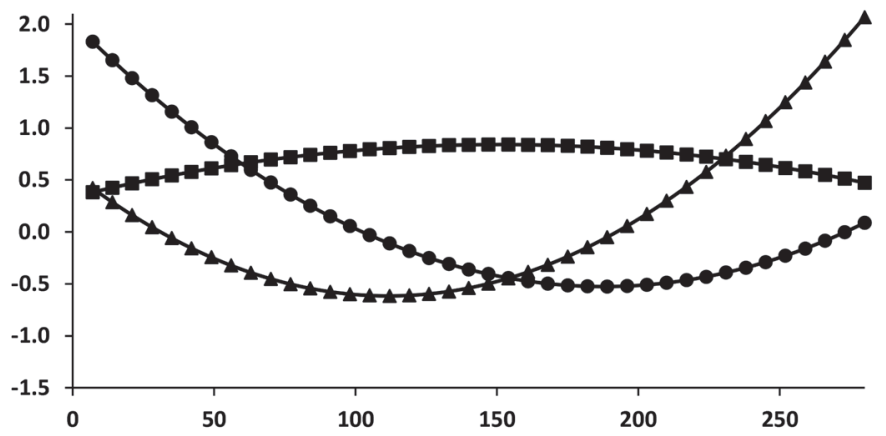

c)

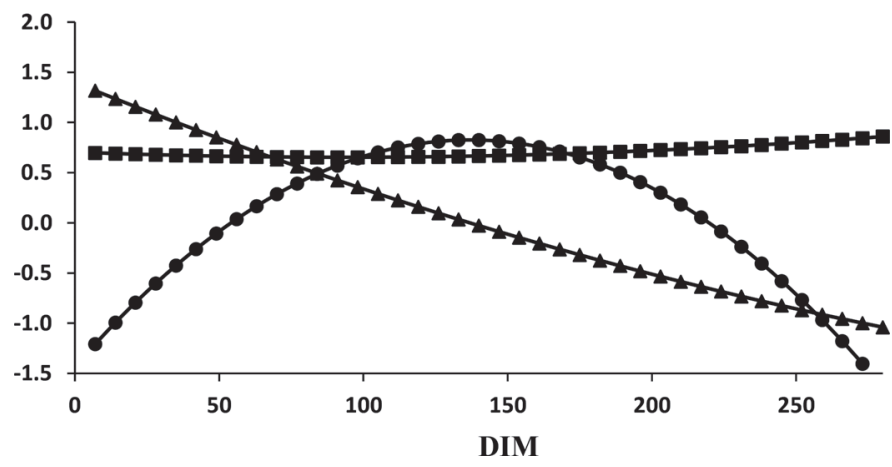

Figure 2. Eigenfunctions (y-axis) associated with the largest (ם) middle $(\mathbf{\Lambda})$, and smallest $(\bullet)$ eigenvalue for (a) energy conversion efficiency, (b) residual energy intake, and (c) residual energy production.

and late-lactation stages. Energy balance and BCS were negatively genetically correlated in early lactation $(-0.34 \pm 0.24$ at $8 \mathrm{DIM})$, but changed sign in very late lactation $(0.23 \pm 0.17$ at $220 \mathrm{DIM})$.

Genetic correlations across lactation between ECE with REI, REP, NEI, $\mathrm{NE}_{\mathrm{L}}$, BW, and BCS are in Figure 6. Energy conversion efficiency was strongly correlated with REP throughout all lactation stages. The genetic correlations between ECE with both NEI and $\mathrm{NE}_{\mathrm{L}}$ followed a similar trend across DIM, but correlations differed in magnitude (Figure 6). Energy conversion efficiency was strongly correlated with MEff at the onset of lactation $(-0.98 \pm 0.26$ at 8 DIM $)$ weakening to a moderate correlation at the end of lactation $(-0.49$ \pm 0.24 at $280 \mathrm{DIM})$. The genetic correlations between ECE and KR strengthened from early to late lactation $(0.53 \pm 0.16$ at 8 DIM to $0.91 \pm 0.14$ at $280 \mathrm{DIM})$.

Genetic correlations between REI with KR, REP, $\mathrm{NEI}, \mathrm{NE}_{\mathrm{L}}, \mathrm{BW}$, and BCS are in Figure 7. Residual energy intake and REP were not correlated in very early lactation $(0.004 \pm 0.34$ at $8 \mathrm{DIM})$, but a moderately negative genetic correlation existed in late lactation $(-0.35 \pm 0.14$ at 280 DIM). Residual energy intake was strongly genetically correlated with NEI in mid lactation (0.89 \pm 0.24 at 209 DIM), although the same correlations at the onset of lactation were moderate $(0.42 \pm 0.15$ at 8 DIM $)$. The correlation between REI and $\mathrm{NE}_{\mathrm{L}}$ followed a curvilinear trend with the strongest correlation $(0.61 \pm 0.14)$ existing in mid lactation $(145$ DIM).

Genetic correlations between REP with MEff, KR, NEI, $\mathrm{NE}_{\mathrm{L}}, \mathrm{BW}$, and BCS are in Figure 8. Strong genetic correlations existed between REP with KR (varying from $0.92 \pm 0.15$ at 280 DIM to $0.98 \pm 0.22$ at 8 $\mathrm{DIM}$ ), and with $\mathrm{NE}_{\mathrm{L}}$ (varying from $0.80 \pm 0.07$ at 214 DIM to $0.88 \pm 0.15$ at 8 DIM) throughout lactation. Residual energy production was moderately genetically correlated with NEI in early lactation $(0.37 \pm 0.16$ at 8 DIM), but was uncorrelated in late lactation (0.01 \pm 0.11 at $280 \mathrm{DIM})$.

\section{DISCUSSION}

Major improvements in dairy cows in gross feed efficiency have been achieved in the past decades as a consequence of principally selecting for increased productivity, thereby diluting maintenance requirements (Bauman et al., 1985; VandeHaar et al., 2016). The genetic merit of current dairy cattle populations must nonetheless be further improved particularly to improve feed utilization and thereby assist the supply of global human demand for animal-derived energy and protein sources. Debate is ongoing as to the best approach to select for improved feed efficiency in lactating animals including cows (Connor et al., 2013; Macdonald et al., 2014; Pryce et al., 2014; Connor, 2015). The objective of the present study was to estimate, using random regression models, the genetic (co)variances across lactation for a range of alternative measures of feed efficiency (i.e., ratio and residual traits) in grazing lactating dairy cows. The results clearly indicate that ample genetic variation exists for (net) feed efficiency in lactating dairy cows, but this variability, as well as their respective heritability estimates, varied across lactation. Selection for feed efficiency in dairy cattle has historically relied upon approximations of maintenance energy requirements based on measurements of BW (Visscher et al., 1994) concurrent with selection for 


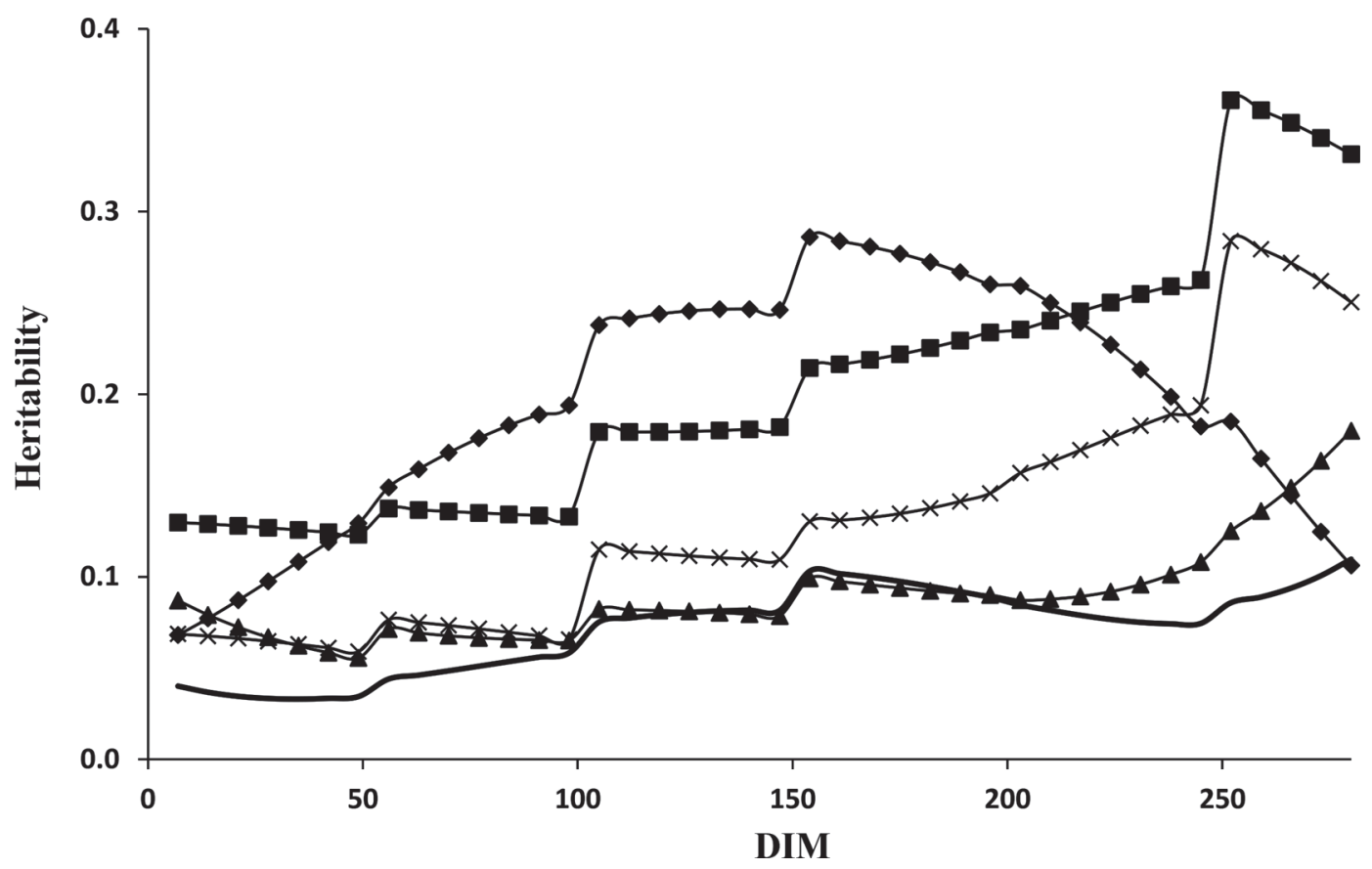

Figure 3. Heritability estimates (SE in parentheses) for energy balance ( $\mathbf{\Lambda} ; 0.04$ to 0.07$)$, energy conversion efficiency ( $\times$; 0.02 to 0.08$)$, residual energy intake ( $-; 0.03$ to 0.06$)$, residual energy production $(\mathbf{\square} ; 0.03$ to 0.07$)$, and net energy intake $(\checkmark ; 0.03$ to 0.06$)$.

increased yields. Such an approach, however, is unlikely to capture all the variability in feed efficiency. In the present study, on average $41 \%$ (varied from 35 to $44 \%$ ) of the genetic variation in daily NEI was associated with differences in genetic merit for BW. One approach for capturing the remaining genetic variability in feed intake is through REI (i.e., net feed efficiency; Koch et al., 1963). Analysis of the eigenvalues and associated eigenfunctions of the additive genetic covariance matrices in the present study suggests there is scope to alter the shape of the lactation profile for the efficiency traits as some of the eigenfunctions changed sign throughout lactation; however, most of the potential from breeding lies in the ability to alter the height of the lactation profiles. To the best of our knowledge, this is the first and most comprehensive study that considers the genetics of feed efficiency across an entire lactation in grazing dairy cows.

\section{The Existence of Genetic Variation}

The presence of genetic variation in all feed efficiency metrics investigated in the present study signify that it is indeed possible to breed for improved efficiency and is consistent with reports elsewhere in lactating and growing cattle (Berry and Crowley, 2013). The exaggerated increase in the genetic variance of the different traits on both peripheries of the lactation is likely due to the mathematical properties of a polyno- mial as relatively more weight is placed on observations at extremities of the parameter space (Meyer, 1998), and this is consistent with observations in other studies that used random regression models for a range of performance traits (Berry et al., 2003; Bohmanova et al., 2008). Furthermore, the larger residual variance in the stage of lactation immediately postparturition is likely due to factors such as calving difficulty and animal health, both of which can affect subsequent performance (Berry et al., 2007; Proudfoot et al., 2009) yet were not accounted for in the statistical model used in the present study due to a lack of available data.

The estimated genetic variance for REI in the present study was consistent with previous results using random regression models applied to lactating dairy cows (Tempelman et al., 2015). The fact that the genetic variance for NEI was greatest in mid lactation agrees with the studies of both Veerkamp and Thompson (1999) using Holstein heifers, and Li et al. (2016) using different breeds of dairy cows (i.e., Holstein, Nordic Red, and Jersey).

Heritability estimates for the majority of the efficiency traits concur with most other international studies from cows offered TMR diets in confinement systems (Berry and Crowley, 2013; Tempelman et al., 2015). Nonetheless, the heritability for REI in the present study was greater than the average of 0.04 reported by Berry and Crowley (2013) from a meta-analysis of the available literature in lactating dairy cows. However, the 
estimated heritability for REI in the present study was less than heritability estimates of 0.22 to 0.38 reported previously in growing dairy heifers (Williams et al., 2011; Pryce et al., 2012). Furthermore, the heritability of REI estimated in the present study was generally the lowest of all the feed efficiency traits considered in the present study, implying that more feed intake records would be required to achieve as high an accuracy of

a)

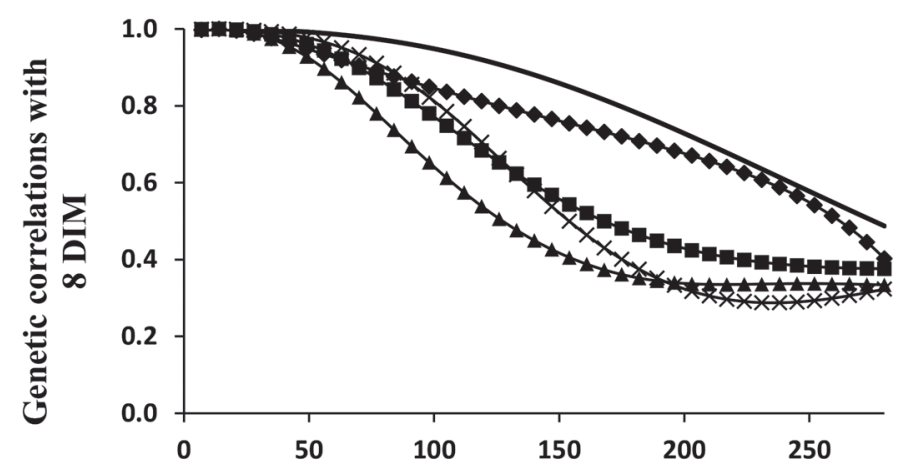

b)

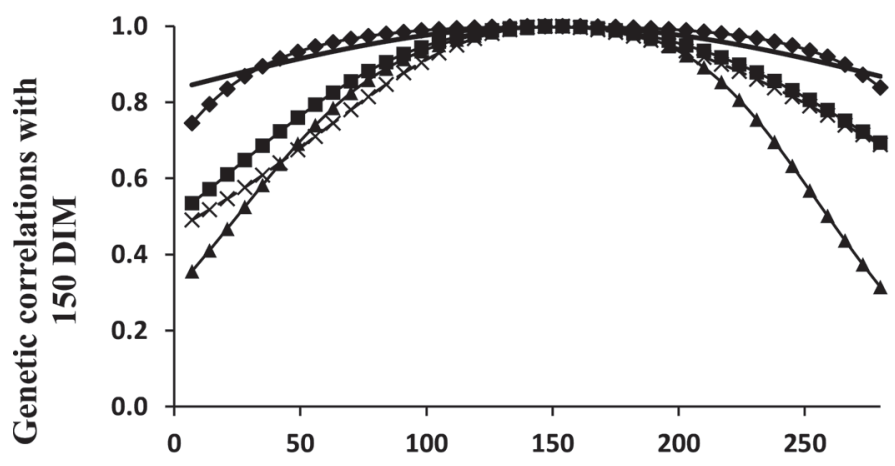

c)

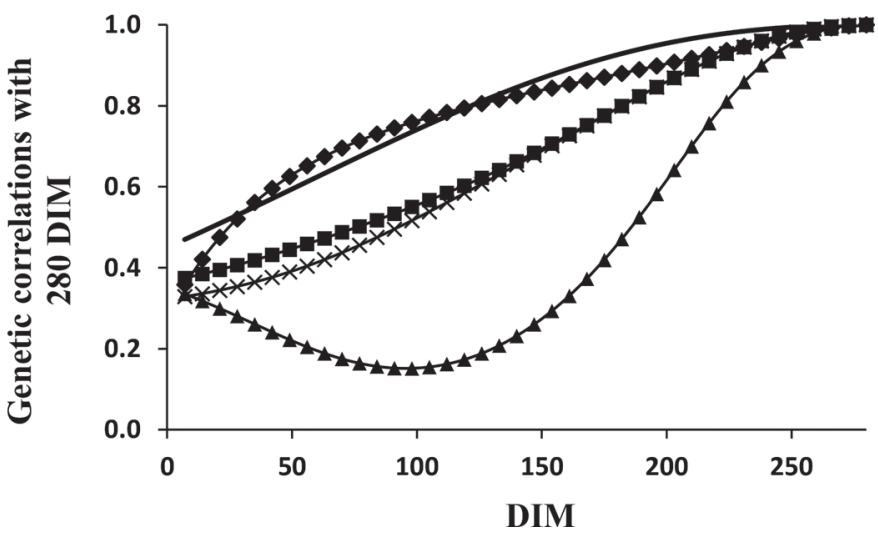

Figure 4. Genetic correlations (SE in parentheses) between observations at (a) 8 DIM, (b) 150 DIM, and (c) 280 DIM for energy balance $(\boldsymbol{\Delta} ; 0.00$ to 0.02$)$, energy conversion efficiency $(\times ; 0.00$ to 0.01$)$, residual energy intake (-; 0.00 to 0.01$)$, residual energy production $(\boldsymbol{\square} ; 0.00$ to 0.02$)$, and net energy intake $(\bullet ; 0.00$ to 0.01$)$. selection as the other feed efficiency traits. Estimated heritability of NEI in the present study was slightly lower than heritability estimates on predominately Holstein cows published elsewhere (0.15 to 0.40; Vallimont et al., 2010; Spurlock et al., 2012; Manzanilla-Pech et al., 2016); nonetheless, heritability estimates for NEI in the present study were greatest in mid lactation, agreeing with other studies based on lactating Holstein cows (Spurlock et al., 2012).

Given that the greatest genetic variation (and heritability) for REI exists in mid to late lactation, first principles of genetic selection (Rendel and Robertson, 1950) would advise selection on REI at this lactation stage; a higher accuracy of selection could also be achieved given the higher heritability of REI in this period of lactation. If REI is included in the breeding goal with reproductive and health traits, however, genetic gain could still be slow (depending on its relative importance). Moreover, genetic gain in the other traits, in particular reproduction and health traits or others also antagonistically correlated with REI (or energy balance), will also reduce. As a result, the long-term efficiency of the animal over its lifetime could actually be compromised in pursuit of gains in efficiency over a certain period (e.g., per lactation). Precise estimates of the genetic correlations between REI and other traits in the breeding goal are therefore crucial, and selection index theory should be used to estimate the expected responses to selection for all traits in the revised breeding goal.

An alternative approach to including REI explicitly in the breeding goal would simply be to include NEI itself as well as the energy sink traits in a breeding goal with the appropriate weighting. Such an approach is known to be mathematically equivalent to explicitly including REI in the breeding goal if all the economic and genetic parameters in the breeding goal are correct (Van der Werf, 2004). As NEI had the greatest genetic variation and heritability in mid lactation, selection at this stage of lactation could lead to the greatest genetic gain. However, estimating NEI on large numbers of animals for use in genetic evaluations is expensive, although alternatives such as predicting NEI from milk mid-infrared spectroscopy exist (McParland et al., 2014).

\section{Correlations Within and Among Traits}

The fact that the genetic correlations among the various efficiency traits were almost all less than unity agrees with the phenotypic analysis of Hurley et al. (2016) on a subset of the data used in the present study and suggests that the efficiency traits investigated are all measuring distinctly different components of effi- 


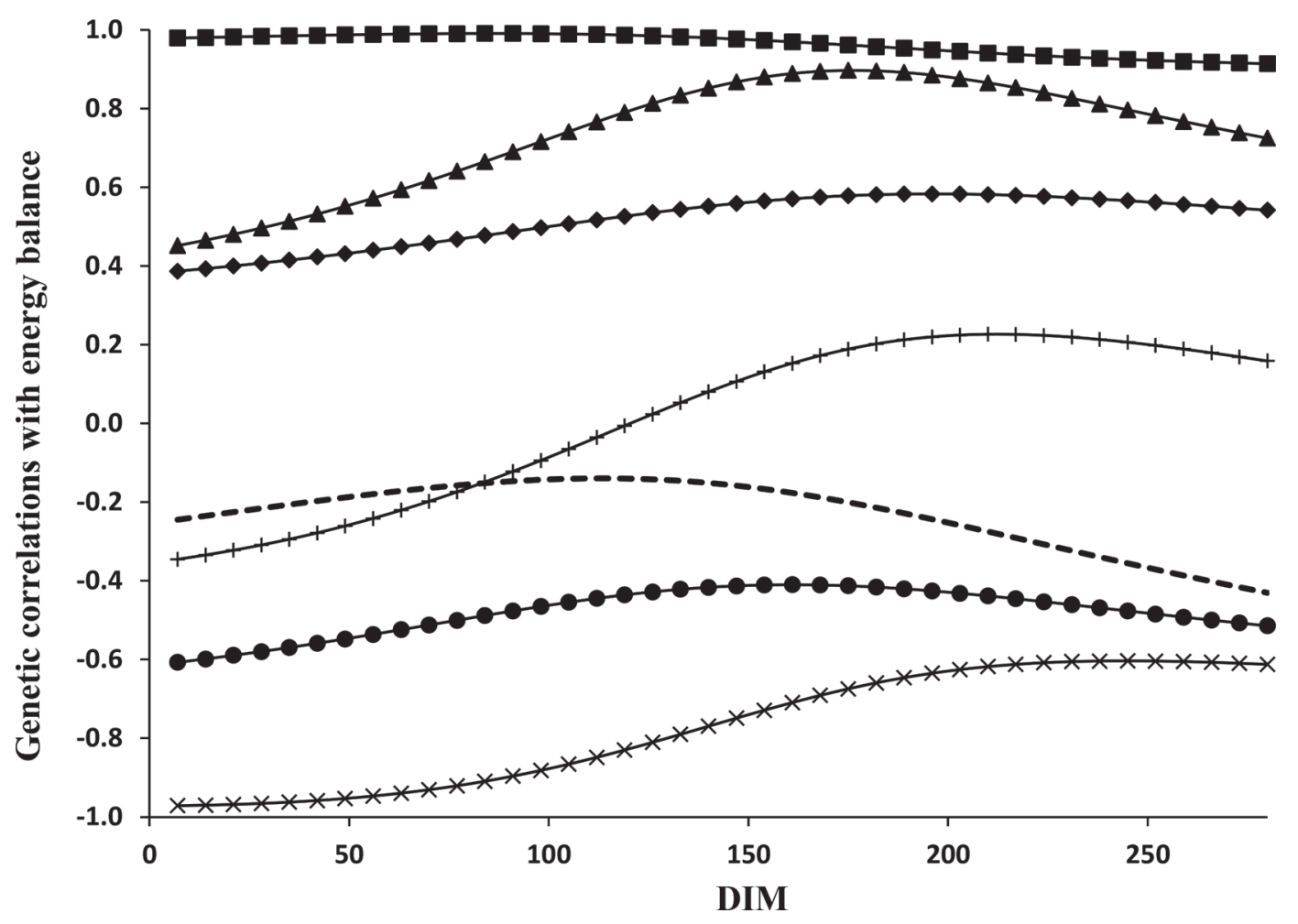

Figure 5. Genetic correlations (SE in parentheses) between energy balance with energy conversion efficiency $(\times ; 0.17$ to 0.21$)$, metabolic efficiency $(\boldsymbol{\square} ; 0.21$ to 0.27$)$, residual energy intake $(\mathbf{\Lambda} ; 0.06$ to 0.18$)$, residual energy production $(\mathbf{\bullet} ; 0.07$ to 0.14$)$, net energy intake $(\checkmark ; 0.14$ to 0.24 ), net energy of lactation (- - ; 0.08 to 0.21 ), and BCS (+; 0.16 to 0.29 ).

ciency. Moreover, the strength of the genetic correlations within each efficiency trait at different DIM sometimes deviated from 1, suggesting the same efficiency traits could be governed by different genetic mechanisms throughout lactation. This is not unexpected given that most of the efficiency traits are a function of at least 2 performance traits (i.e., milk production and live weight), and the contribution of these traits to the feed efficiency definition will vary as the respective variances changes during lactation. Such phenomena need consideration when contemplating including feed efficiency traits in a breeding program. Nonetheless, in general the weakest genetic correlation among records for the same trait were rarely less than 0.80 for REI, KR, and FtW; Robertson (1959) stated that if correlations between the same trait in 2 environments was $>0.80$, then they could be considered the same trait. Therefore, although the genetic correlations for the same trait in different stages of lactation differed from unity, for some efficiency traits, they could be considered the same during the lactation with minimal repercussions. Of greater concern, however, was the relatively weak genetic correlation that existed between REI at the extreme DIM. Such a weak correlation for REI could be due to the physiological changes of lacta- tion and its effect on the partition of NEI into the different components across lactation. The strength of the genetic correlations between NEI at different DIM was very similar to the genetic correlations between REI at different stages of lactation.

Hurley et al. (2016), using a subset of the data used in the present study, reported strong phenotypic correlations between REI and EB and justified this correlation based on the mathematical equations underlying both REI and EB. The strong positive genetic correlation between REI and EB in the present study indicates selection on lower REI (i.e., deemed efficient cows) would favor cows with a lower energy status, and this correlation was strongest in mid lactation when live weight change was least (Hurley et al., 2016). Although unfavorable genetic correlations have been reported between greater negative energy balance and both reproductive performance (Beam and Butler, 1999) and health (Collard et al., 2000), selection for REI within a balanced breeding goal could be used to overcome such antagonisms (Berry and Crowley, 2013). In the present study, positive genetic correlations existed between REI and NEI, which is supported by earlier studies also on dairy cows (Van Arendonk et al., 1991; Vallimont et al., 2011; Manafiazar et al., 2016). Possible reasons for 
genetic correlations between REI and its component traits have been discussed in beef (Crews, 2005) and dairy cattle (Kennedy et al., 1993).

In the present study, strong genetic correlations existed among some of the ratio traits, EB, and production traits. The observed stronger genetic correlation between ECE with $\mathrm{NE}_{\mathrm{L}}$ was predominately caused by the larger coefficient of genetic variation for $\mathrm{NE}_{\mathrm{L}}$ (6.74\%) compared with the coefficient of genetic variation for NEI (4.82\%). The generally strong genetic correlations between $\mathrm{ECE}$ and $\mathrm{NE}_{\mathrm{L}}$ were in agreement with previous studies on dairy cows (Prendiville et al., 2009; Spurlock et al., 2012). Moreover, the moderately negative genetic correlations between ECE with both BCS and BW could potentially indicate that the loss of both BCS and BW throughout lactation contributes to higher (i.e., superior) ECE values. The strong genetic correlation which existed between ECE and EB signify that cows with a higher ECE (i.e., more efficient cows) were also in more negative EB. The unfavorable implications of negative EB on health and fitness traits have been well documented (Beam and Butler, 1999; Collard et al., 2000). Of particular interest in the present study was the change in sign of the genetic correlation between EB and BCS. The moderately negative genetic correlation between EB and BCS in early lactation indicates that fatter cows, on average, are genetically predisposed to mobilizing more body condition in early lactation as concluded by Berry et al. (2002). However, the change in sign of the genetic correlation between $\mathrm{EB}$ and $\mathrm{BCS}$ in mid lactation (i.e., at 121 DIM) suggests that cows in greater positive EB put on more body condition.

\section{Potential to Alter Lactation Profiles}

The use of random regression animal models facilitates the calculation of breeding values for the particular trait of interest across each DIM but also enables the quantification of the potential to genetically alter the lactation profile (Kirkpatrick et al., 1990). The structure of the eigenfunctions and size of the associated eigenvalues give an indication of the extent to which the lactation curve can be altered (Kirkpatrick et al., 1990). The sign of the eigenfunctions is irreverent, but instead what matters is the consistency, or lack thereof, of the sign of the eigenfunctions over the trajectory (van der Werf and Schaeffer, 1997). The eigenfunctions associated with $11.22 \%$ (middle) and $8.90 \%$ (smallest) of the genetic variance for REI changed sign across

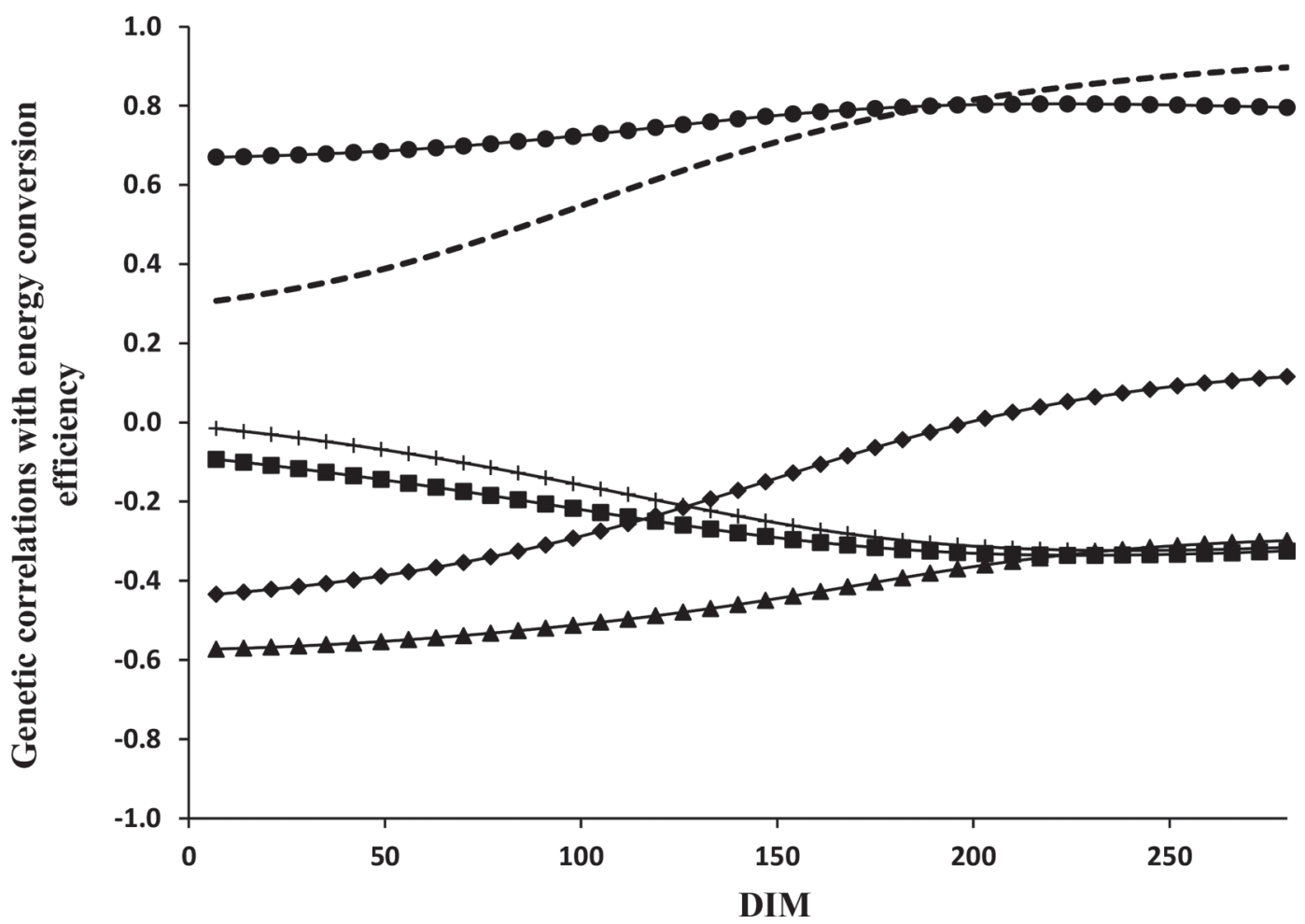

Figure 6. Genetic correlations (SE in parentheses) between energy conversion efficiency with residual energy intake ( $\mathbf{\Delta} ; 0.21$ to 0.30$)$, residual

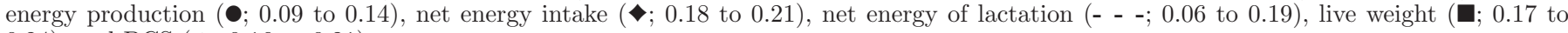
$0.24)$, and BCS (+; 0.16 to 0.21$)$. 


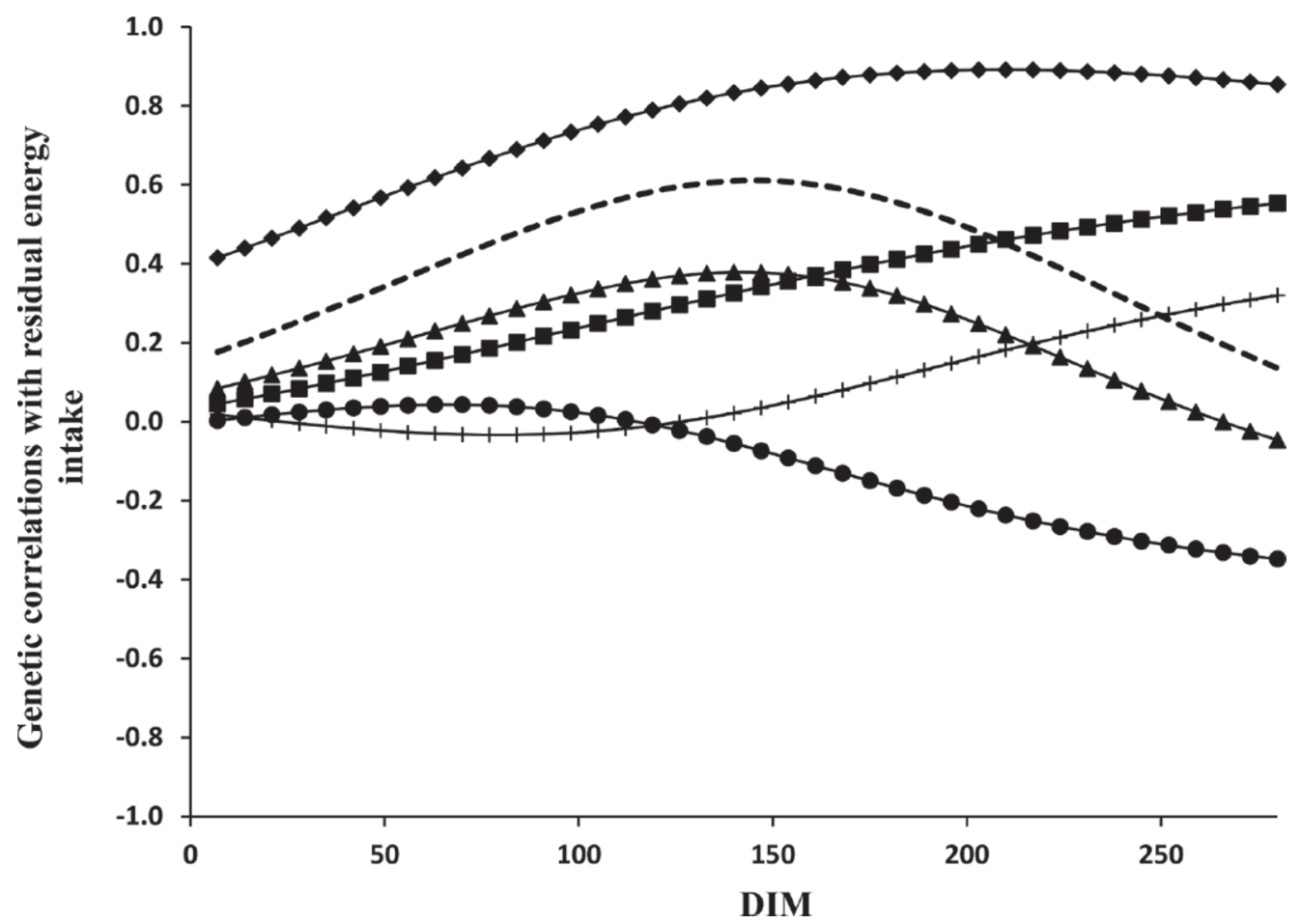

Figure 7. Genetic correlations (SE in parentheses) between residual energy intake with Kleiber ratio ( $\mathbf{\Lambda} ; 0.06$ to 0.14$)$, residual energy pro-

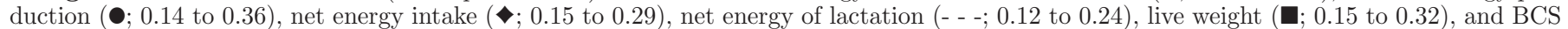
$(+; 0.13$ to 0.25$)$.

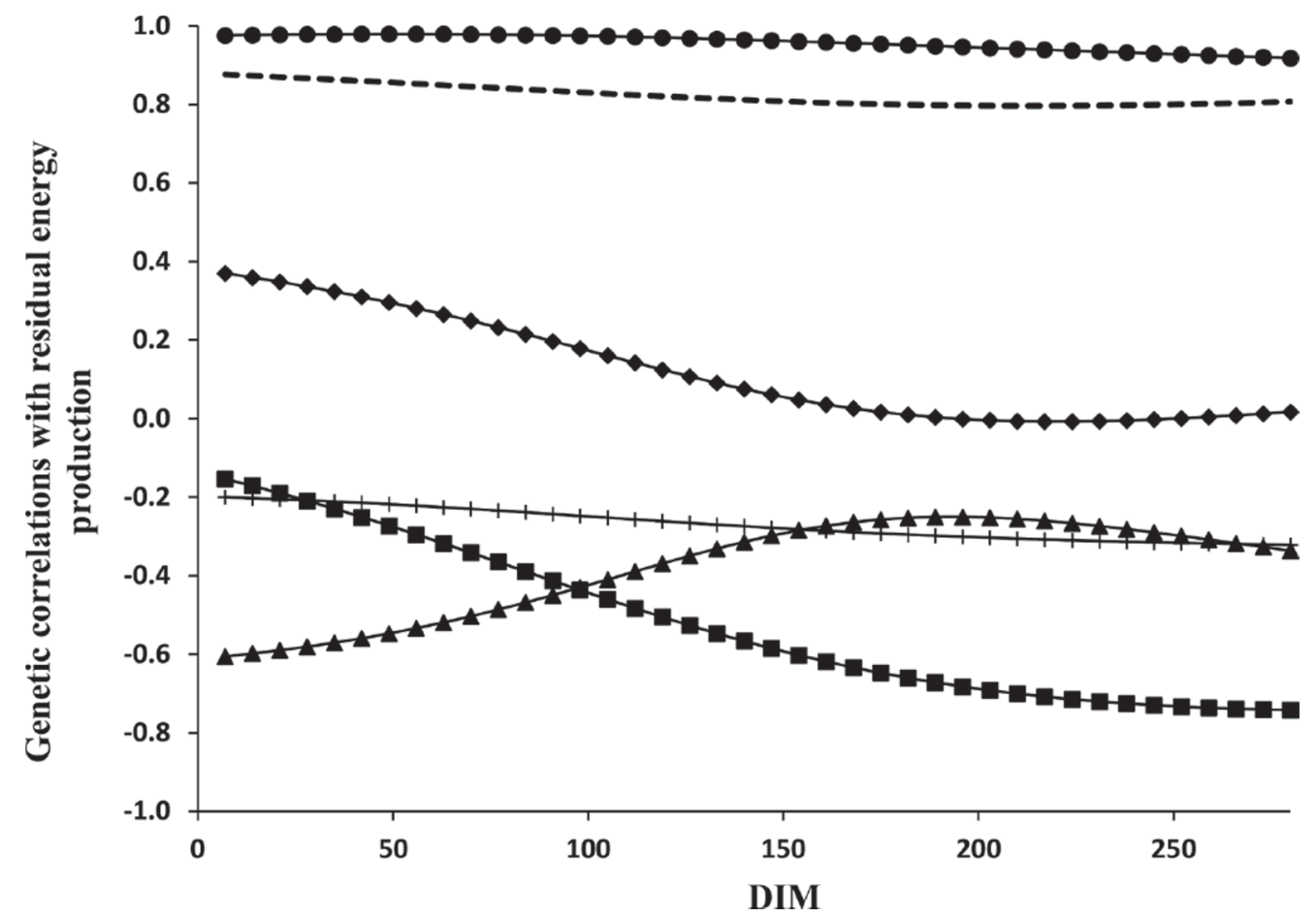

Figure 8. Genetic correlations (SE in parentheses) between residual energy production with metabolic efficiency ( $\mathbf{\Lambda} ; 0.11$ to 0.18 ), Kleiber ratio (- 0.11 to 0.22 ), net energy intake ( 0.09 to 0.16 ), net energy of lactation (- - ; 0.07 to 0.16 ), live weight ( $\mathbf{\square}$; 0.08 to 0.19$)$, and BCS $(+; 0.11$ to 0.21$)$. 
lactation, implying that REI is indeed under different genetic control across different stages of lactation but also indicates the potential to alter the shape of the REI lactation profile. However, as the height of the covariance function explained the largest proportion (i.e., $>70 \%$ ) of the genetic variation, strategies to alter the shape of the lactation profile, would require greater selection pressure on the relevant eigenfunction.

\section{CONCLUSIONS}

This is the first study to comprehensively describe the genetic inter-relationships among alternative definitions of energy efficiency in lactating dairy cows. Results clearly indicate that ample genetic variation exists for all feed efficiency traits in lactating dairy cows, but this variability, as well as their respective heritability estimates, varies across lactation. Of particular interest is that the results suggest that selection for decreased REI should result in genetically superior animals for energy efficiency without any compromise in productivity. Moreover, potential exists to select on the trajectories of the efficiency traits (i.e., ECE, REI, and REP) to alter the shape of the lactation profile to suit a particular breeding objective. The moderate to strong genetic correlations estimated between REI and $\mathrm{EB}$ are worrying for the effect of selection of REI on lifetime efficiency. Nonetheless, precise genetic correlations between the feed efficiency complex with both reproduction and health traits need to be quantified.

\section{ACKNOWLEDGMENTS}

Funding from the Irish Department of Agriculture, Food and Marine (Dublin, Ireland) Research Stimulus Fund project GENCOST and funding from the Marie Curie project International Research Staff Exchange Scheme SEQSEL are greatly appreciated.

\section{REFERENCES}

Agabriel, J. 2007. Alimentation des bovins, ovins et caprins: besoins des animaux, valeurs des aliments: Tables INRA 2007. Editions Quae.

Bauman, D. E., S. N. McCutcheon, W. D. Steinhour, P. J. Eppard, and S. J. Sechen. 1985. Sources of variation and prospects for improvement of productive efficiency in the dairy cow: A review. J. Anim. Sci. 60:583-592.

Beam, S. W., and W. R. Butler. 1999. Effects of energy balance on follicular development and first ovulation in postpartum dairy cows. J. Reprod. Fertil. Suppl. 54:411-424.

Berry, D. P., F. Buckley, P. Dillon, R. D. Evans, M. Rath, and R. F. Veerkamp. 2002. Genetic parameters for level and change of body condition score and body weight in dairy cows. J. Dairy Sci. 85:2030-2039.

Berry, D. P., F. Buckley, P. Dillon, R. D. Evans, M. Rath, and R. F. Veerkamp. 2003. Genetic parameters for body condition score, body weight, milk yield, and fertility estimated using random regression models. J. Dairy Sci. 86:3704-3717.

Berry, D. P., M. P. Coffey, J. E. Pryce, Y. De Haas, P. Løvendahl, N. Krattenmacher, J. J. Crowley, Z. Wang, D. Spurlock, K. Weigel, and K. Macdonald. 2014. International genetic evaluations for feed intake in dairy cattle through the collation of data from multiple sources. J. Dairy Sci. 97:3894-3905.

Berry, D. P., and J. J. Crowley. 2013. Genetics of feed efficiency in dairy and beef cattle. J. Anim. Sci. 91:1594-1613.

Berry, D. P., J. M. Lee, K. A. Macdonald, and J. R. Roche. 2007. Body condition score and body weight effects on dystocia and stillbirths and consequent effects on postcalving performance. J. Dairy Sci. 90:4201-4211.

Bohmanova, J., F. Miglior, J. Jamrozik, I. Misztal, and P. G. Sullivan. 2008. Comparison of random regression models with Legendre polynomials and linear splines for production traits and somatic cell score of Canadian Holstein cows. J. Dairy Sci. 91:3627-3638.

Coleman, J., D. P. Berry, K. M. Pierce, A. Brennan, and B. Horan 2010. Dry matter intake and feed efficiency profiles of 3 genotypes of Holstein-Friesian within pasture-based systems of milk production. J. Dairy Sci. 93:4318-4331.

Collard, B. L., P. J. Boettcher, J. C. M. Dekkers, D. Petitclerc, and L. R. Schaeffer. 2000. Relationships between energy balance and health traits of dairy cattle in early lactation. J. Dairy Sci. 83:2683-2690.

Connor, E. E. 2015. Invited review: Improving feed efficiency in dairy production: Challenges and possibilities. Animal 9:395-408

Connor, E. E., J. L. Hutchison, H. D. Norman, K. M. Olson, C. P. Van Tassell, J. M. Leith, and R. Baldwin. 2013. Use of residual feed intake in Holsteins during early lactation shows potential to improve feed efficiency through genetic selection. J. Anim. Sci. 91:3978-3988.

Crews, D. H. Jr. 2005. Genetics of efficient feed utilization and national cattle evaluation: a review. Genet. Mol. Res. 4:152-165.

de Haas, Y., J. E. Pryce, M. P. L. Calus, E. Wall, D. P. Berry, P. Løvendahl, N. Krattenmacher, F. Miglior, K. Weigel, D. Spurlock, K. A. Macdonald, B. Hulsegge, and R. F. Veerkamp. 2015. Genomic prediction of dry matter intake in dairy cattle from an international data set consisting of research herds in Europe, North America, and Australasia. J. Dairy Sci. 98:6522-6534.

Dillon, P., S. Crosse, G. Stakelum, and F. Flynn. 1995. The effect of calving date and stocking rate on the performance of springcalving dairy cows. Grass Forage Sci. 50:286-299.

Edmonson, A. J., I. J. Lean, L. D. Weaver, T. Farver, and G. Webster. 1989. A body condition scoring chart for Holstein dairy cows. J. Dairy Sci. 72:68-78.

Emmerson, D. A. 1997. Commercial approaches to genetic selection for growth and feed conversion in domestic poultry. Poult. Sci. $76: 1121-1125$

Falconer, D. S., and T. F. C. MacKay. 1996. Introduction to Quantitative Genetics. 4th ed. Longman Group Ltd., London, UK.

Fischer, T. M., A. R. Gilmour, and J. H. Van der Werf. 2004. Computing approximate standard errors for genetic parameters derived from random regression models fitted by average information REML. Genet. Sel. Evol. 36:363-369.

Gilmour, A. R., B. Gogel, B. Cullis, R. Thompson, and D. Butler. 2009. ASReml user guide release 3.0. VSN International Ltd., Hemel Hempstead, UK.

Hurley, A. M., N. López-Villalobos, S. McParland, E. Kennedy, E. Lewis, M. O'Donovan, J. L. Burke, and D. P. Berry. 2016. Interrelationships among alternative definitions of feed efficiency in grazing lactating dairy cows. J. Dairy Sci. 99:468-479.

Jarrige, R. 1989. Ruminant Nutrition: Recommended Allowances and Feed Tables. Libbey, London, UK.

Kennedy, B., J. H. Van der Werf, and T. H. Meuwissen. 1993. Genetic and statistical properties of residual feed intake. J. Anim. Sci. 71:3239-3250.

Kennedy, E., M. O'Donovan, L. Delaby, and F. P. O'Mara. 2008. Effect of herbage allowance and concentrate supplementation on dry matter intake, milk production and energy balance of early lactating dairy cows. Livest. Sci. 117:275-286. 
Kirkpatrick, M., D. Lofsvold, and M. Bulmer. 1990. Analysis of the inheritance, selection and evolution of growth trajectories. Genetics 124:979-993.

Kleiber, M. 1961. The Fire of Life. An Introduction to Animal Energetics. Wiley, New York, NY.

Koch, R. M., L. A. Swiger, D. Chambers, and K. E. Gregory. 1963. Efficiency of feed use in beef cattle. J. Anim. Sci. 22:486-494.

Li, B., W. F. Fikse, J. Lassen, M. H. Lidauer, P. Løvendahl, P. Mäntysaari, and B. Berglund. 2016. Genetic parameters for dry matter intake in primiparous Holstein, Nordic Red, and Jersey cows in the first half of lactation. J. Dairy Sci. 99:7232-7239.

Lonergan, S. M., E. Huff-Lonergan, L. J. Rowe, D. L. Kuhlers, and S. B. Jungst. 2001. Selection for lean growth efficiency in Duroc pigs influences pork quality. J. Anim. Sci. 79:2075-2085.

Macdonald, K. A., J. E. Pryce, R. J. Spelman, S. R. Davis, W. J. Wales, G. C. Waghorn, Y. J. Williams, L. C. Marett, and B. J. Hayes. 2014. Holstein-Friesian calves selected for divergence in residual feed intake during growth exhibited significant but reduced residual feed intake divergence in their first lactation. J. Dairy Sci. 97:1427-1435.

Manafiazar, G., L. Goonewardene, F. Miglior, D. H. Crews, J. A. Basarab, E. Okine, and Z. Wang. 2016. Genetic and phenotypic correlations among feed efficiency, production and selected conformation traits in dairy cows. Animal 10:381-389.

Manzanilla-Pech, C. I. V., R. F. Veerkamp, M. P. L. Calus, R. Zom, A. van Knegsel, J. E. Pryce, and Y. De Haas. 2014. Genetic parameters across lactation for feed intake, fat-and protein-corrected milk, and liveweight in first-parity Holstein cattle. J. Dairy Sci. 97:5851-5862.

Manzanilla-Pech, C. I. V., R. F. Veerkamp, R. Tempelman, M. van Pelt, K. Weigel, M. VandeHaar, T. Lawlor, D. Spurlock, L. Armentano, and C. Staples. 2016. Genetic parameters between feedintake-related traits and conformation in 2 separate dairy populations-the Netherlands and United States. J. Dairy Sci. 99:443-457.

Mayes, R. W., C. S. Lamb, and P. M. Colgrove. 1986. The use of dosed and herbage n-alkanes as markers for the determination of herbage intake. J. Agric. Sci. 107:161-170.

McParland, S., E. Lewis, E. Kennedy, S. G. Moore, B. McCarthy, M. O'Donovan, S. T. Butler, J. E. Pryce, and D. P. Berry. 2014. Mid-infrared spectrometry of milk as a predictor of energy intake and efficiency in lactating dairy cows. J. Dairy Sci. 97:5863-5871.

Meyer, K. 1998. Estimating covariance functions for longitudinal data using a random regression model. Genet. Sel. Evol. 30:221-240.

O'Mara, F. 1996. A net energy system for cattle and sheep. Department of Animal Science and Production, University College Dublin, Dublin, Ireland.

Oltenacu, P. A., and D. M. Broom. 2010. The impact of genetic selection for increased milk yield on the welfare of dairy cows. Anim. Welf. 19:39-49.

Prendiville, R., K. M. Pierce, and F. Buckley. 2009. An evaluation of production efficiencies among lactating Holstein-Friesian, Jersey, and Jersey $\times$ Holstein-Friesian cows at pasture. J. Dairy Sci. 92:6176-6185.

Proudfoot, K. L., J. M. Huzzey, and M. A. G. Von Keyserlingk. 2009. The effect of dystocia on the dry matter intake and behavior of Holstein cows. J. Dairy Sci. 92:4937-4944.
Pryce, J. E., J. Arias, P. J. Bowman, S. R. Davis, K. A. Macdonald, G. C. Waghorn, W. J. Wales, Y. J. Williams, R. J. Spelman, and B. J. Hayes. 2012. Accuracy of genomic predictions of residual feed intake and 250-day body weight in growing heifers using 625,000 single nucleotide polymorphism markers. J. Dairy Sci. 95:2108-2119.

Pryce, J. E., W. J. Wales, Y. De Haas, R. F. Veerkamp, and B. J. Hayes. 2014. Genomic selection for feed efficiency in dairy cattle. Animal 8:1-10.

Rendel, J. M., and A. Robertson. 1950. Estimation of genetic gain in milk yield by selection in a closed herd of dairy cattle. J. Genet. $50: 1-8$.

Robertson, A. 1959. The sampling variance of the genetic correlation coefficient. Biometrics 15:469-485.

Spurlock, D. M., J. C. M. Dekkers, R. Fernando, D. A. Koltes, and A. Wolc. 2012. Genetic parameters for energy balance, feed efficiency, and related traits in Holstein cattle. J. Dairy Sci. 95:5393-5402.

Tempelman, R. J., D. M. Spurlock, M. Coffey, R. F. Veerkamp, L. E. Armentano, K. A. Weigel, Y. De Haas, C. R. Staples, E. E. Connor, Y. Lu, and M. J. VandeHaar. 2015. Heterogeneity in genetic and nongenetic variation and energy sink relationships for residual feed intake across research stations and countries. J. Dairy Sci. 98:2013-2026.

Vallimont, J. E., C. D. Dechow, J. M. Daubert, M. W. Dekleva, J. W. Blum, C. M. Barlieb, W. Liu, G. A. Varga, A. J. Heinrichs, and C. R. Baumrucker. 2010. Genetic parameters of feed intake, production, body weight, body condition score, and selected type traits of Holstein cows in commercial tie-stall barns. J. Dairy Sci. 93:4892-4901.

Vallimont, J. E., C. D. Dechow, J. M. Daubert, M. W. Dekleva, J. W. Blum, C. M. Barlieb, W. Liu, G. A. Varga, A. J. Heinrichs, and C. R. Baumrucker. 2011. Short communication: Heritability of gross feed efficiency and associations with yield, intake, residual intake, body weight, and body condition score in 11 commercial Pennsylvania tie stalls. J. Dairy Sci. 94:2108-2113.

Van Arendonk, J. A. M., G. J. Nieuwhof, H. Vos, and S. Korver. 1991. Genetic aspects of feed intake and efficiency in lactating dairy heifers. Livest. Prod. Sci. 29:263-275.

van der Werf, J. H. J. 2004. Is it useful to define residual feed intake as a trait in animal breeding programs? Anim. Prod. Sci. 44:405-409.

van der Werf, J. H. J., and L. R. Schaeffer. 1997. Random regression in animal breeding. Course notes. CGIL, University of Guelph, Guelph, Canada.

VandeHaar, M. J., L. E. Armentano, K. Weigel, D. M. Spurlock, R. J. Tempelman, and R. Veerkamp. 2016. Harnessing the genetics of the modern dairy cow to continue improvements in feed efficiency. J. Dairy Sci. 99:4941-4954.

Veerkamp, R. F., and R. Thompson. 1999. A covariance function for feed intake, live weight, and milk yield estimated using a random regression model. J. Dairy Sci. 82:1565-1573.

Visscher, P. M., P. J. Bowman, and M. E. Goddard. 1994. Breeding objectives for pasture based dairy production systems. Livest. Prod. Sci. 40:123-137.

Williams, Y. J., J. E. Pryce, C. Grainger, W. J. Wales, N. Linden, M. Porker, and B. J. Hayes. 2011. Variation in residual feed intake in Holstein-Friesian dairy heifers in southern Australia. J. Dairy Sci. 94:4715-4725. 